\title{
A legal perspective on grid interconnection of renewable energy and the role of electric utilities
}

\author{
Ju-Yin Chen* \\ School of Law, Soochow University, 56 Kueiyang Street, Section 1, Taipei, Taiwan 100, R.O.C.
}

\begin{abstract}
Electric power must become less dependent on fossil fuels and thus strong supports for promoting renewable sources such as solar and wind become widespread. The transition is moving slowly, and need legislative, regulatory and market-based electric utility structure cooperate. Nevertheless, in the process of boosting installed capacity from renewable energy, grid interconnection is widely regarded as the most significant barrier since production of wind and solar is dependent on weather and sun which can vary quite dramatically over time. This essay describes the trend of grid interconnection with renewable energy at first, and continues discuss predicament from the concerning laws and contracts, and finally compare the current policy and legislative of grid interconnection in the United States, China and Taiwan. It is emphasized that utility's mandatory purchase obligation is only the subsidy policy matters, and strongly relate to the structure of electricity market. In the near future, the "Mandatory Connection Principle" should be well planned in the Renewable Energy Law and relative regulations.
\end{abstract}

Keywords: Grid interconnection, renewable energy law, electric utility, distributed generation, energy policy

\section{Introduction}

Electric power must become less dependent on fossil fuels and thus there are strong supports for promoting renewable sources such as solar power and wind power both at the global and national levels. The transition is moving slowly, and need legislative, regulatory and market-based electric utility structure cooperate. Nevertheless, in the process of boosting installed capacity from renewable energy, grid interconnection is widely regarded as the most significant barrier since production of wind and solar is dependent on weather and sun which can vary quite dramatically over time. In the past the electric utility - the entities responsible for managing the flow of electricity on the grid - tend to disapprove of interconnection and even may control the processes as a trigger, therefore delay opportunities to boost distributed generation capacity.

This essay will describe the trend of grid interconnection with renewable energy in the first place, and continue to discuss predicament from the concerning laws and contracts, and finally compare the current policy and legislative of grid interconnection in the United States, China as well as Taiwan. Hopefully, this research may provide some point of views for further reform of Electric utility in the era of sustainable energy.

\section{Current Integrating Renewables in the Grid}

Renewable energy is fast becoming a major source of electricity in the U.S. and now generates 13 percent of the nation's electricity. U.S. wind generation capacity is expected to increase from less than 60 Gigawatts (GW) in 2012 to $85 \mathrm{GW}$ in 2040 with an average of $1.3 \%$ a year, while solar energy is expected to be the fastest-growing source at a rate of $7.5 \%$ annually from 2012-2040[1]. There are three

\footnotetext{
* Manuscript received March 15, 2015; revised July 25, 2015.

Corresponding author. Tel.: +886 931-349892; E-mail address: pio362@yahoo.com.tw

doi: 10.12720 /sgce.4.2.146-150
} 
power grids in U.S.- the eastern, western and Texas- now serve as an interlinked system including about 2,000 electric distribution utilities, more than 300,000 miles of transmission and distribution lines, millions of customers, and 7,000 power plants[2]. For aiding in the integration of renewable energy resources, the Federal Energy Regulatory Commission (FERC) which regulates interstate electricity transmission as an independent government agency has issued a number of orders in the past few years include FERC Order No. 745, 755, 764, 784, 792, 1000 addressing regional transmission planning, demand response, energy storage and operational practices. Meanwhile, States are exploring a number of policy actions to help utilities integrate variable renewable resources, including efforts to promote demand response, grid technologies that smooth renewable energy integration, forecasting and transmissions planning. Taking California for example, the state passed two important bills in 2013 and 2014. First, the Assembly Bill 327 opens the door for electric corporations to offer demand response programs and time-variable pricing for residential customers beginning in 2018. And the other Senate Bill 96 direct the Public Utilities Commission to develop and implement a program that will award funds for projects that benefit electricity ratepayers and lead to technological advancement in the areas of energy storage; renewable energy and its integration into the electrical grid; and accurate forecasting of the renewable energy production for integration into the grid.

China exceeded the United States in terms of total electric power generation capacity by 2013. Since total installed renewable capacity reached $380 \mathrm{GW}$ in 2013, wind power had become the second largest source of renewable power accounting for only $2.5 \%$ of the total and solar PV installation capacity come to $13 \mathrm{GW}$ [3]. According to China's REmap 2030, it will has a fivefold increase in onshore wind capacity, from $91 \mathrm{GWe}$ in 2013 to $500 \mathrm{GW}$ by 2030 and an additional $60 \mathrm{GW}$ capacity in offshore wind. In solar PV, China aims to raise the total to $70 \mathrm{GW}$ by 2017 , envisaging a total installed capacity of $308 \mathrm{GW}$ by 2030 with equal contributions from utility-scale and distributed projects [4].

It is gradually getting attentions that better regional coordination to create power exchange and new interconnectors between provinces, as well as power trading with neighbouring countries (such as hydroelectricity from Siberia and Southeast Asia, or wind from Mongolia.) Since China separate generation and transmission functions of power sector for creating competition, the former State Power Corporation of China divided into two grid companies, five generation groups and four accessorial business companies. The two grid (utility) companies which were founded on December 29, 2002 are the State Grid Corporation of China and a smaller China Southern Power Grid Corporation.

Although China enacted The Renewable Energy Law ("REL") which became effective in January 2006 for the emerging renewable energy sector, when power grid companies enter into interconnection agreements with renewable energy projects, the grid company obligated to purchase and dispatch the entire amount of electricity generated [5]. Nevertheless, the legislative framework did not match the unprecedented progress of the renewable energy sector, and the grids have not been able to dispatch all of the potential energy generated. Two of the main arguments are if lagging development of power grids in support of newly-constructed renewable energy sites, and lack of assured interconnection of renewable energy projects to the grid [6].

Under the amended REL effecting on 1 April 2010, even the renewable energy sites were built in remote regions without a developed power grid. Under grid interconnection agreements, electricity generating enterprises must ensure that the renewable energy meets the technical standards for electricity dispatch and cooperate with power grid companies to maintain power grid safety. To further enhance power grid operations, the REL Amendments also require power grid enterprises to improve power transmission technologies and grid capacity to dispatch more power produced by renewable energy generators. Power grid companies are encouraged to adopt advanced technologies, such as smart grids and grid energy storage, to enhance power grid operation and management, which will in turn improve their capacity to absorb the power generated by renewable energy sources.

\section{Interconnection Obligations of Electric Utility}

Now that generation sector needs more clean energy resource to join, consequently competitive 
circumstance becomes necessarily required and the transmission system shoulders the key role as common carrier. Beginning the process of interconnection issues U.S. obligates utilities must allow small energy generation to be interconnected with the grid through the federal Public Utility Regulatory Policies Act (PURPA) enacted in 1978. For renewable energy, The Federal Energy Policy Act of 2005 (EPAct 2005) kick-started these improvements by requiring state public utility commissions to "consider" standards for net metering and interconnection. The legislation required that states determine a netmetering standard by August 8, 2008 and an interconnection standard by August 8, 2007. Nowadays, energy from diversified renewable sources categorized as owner-sited or utility scale systems needs more delicate regulations and procedures. Moreover, the premier 2007 edition of the report, Freeing the Grid, which grades state net metering and interconnection policies, many states have embraced the 'best practices' for promoting distributed generation allowing customers that have distributed energy systems to connect with the grid, and spin their meter backwards when they produce more energy than they use.

Generally speaking, interconnection standards are the legal rules and procedures for "plugging" a renewable energy system into the grid which includes the technical and contractual terms. Most small renewable energy systems can be approved and interconnected quickly; larger systems generally take more time and may require system impact studies to ensure they will not cause any issues on the grid. Accordingly, FERC issued the first version of SGIA \& SGIP for generators no larger than 20 megawatts on May 12, 2005, and then comes the "Standard Interconnection Agreements for Wind Energy and Other Alternative Technologies" including the use of non-synchronous generators and other alternative technologies on December 12, 2005. The latter standard agreements and procedures provide just and reasonable terms for the interconnection of wind plants facilities larger than 20 megawatts. And earlier in 2003, the Large Generator Interconnection Agreement (LGIA) \& Procedures (LGIP) which for the interconnection of generators larger than 20 megawatts were enacted. Recently, FERC issued updated documents of Standard Interconnection Agreements ( SGIA) \& Procedures ( SGIP) for Small Generators on September 19, 2014. These reforms reduce the time and cost to process small generator interconnection requests and zealously help increasing the number and types of new generators available in the electric market.

By comparison, China amended the REL in 2010 strengthening interconnection obligation on utilities. Since lack of grid interconnection standards which is another well-recognized bottleneck for distributed generation, as well as relative agreements, the National Energy Administration and the Administration for Industry \& Commerce National Energy Board also issued the " Standard Agreement for Wind Plant Interconnected with Grid and Dispatching " and the " Standard Agreement for Solar Generation System Interconnected with Grid and Dispatching " in July 2014. It's worth mentioning that these two documents seems apply to power plant which developed by utility-scale projects of China's 12th Five-Year Plan (2011-2015). In other words, China, at this present stage, is actively promoting the large, centralized wind/ solar farms with gigawatt scale, though we only can find the capacity may larger than megawatts from the term of model agreement. Certainly, from 2013, China begin advancing distributed generations; however, due to the business model is not yet fully established, centralized PV station still the majority.

\section{Role of Utility in Interconnected with Smaller Renewables}

Immediately after the foregoing legislative literature, we hereby want to discuss the extent of generator's right, and does utility have to interconnect no matter the capacity of generation's facility. Especially distributed renewable energy is one of the fastest growing sectors in the world, and attention will keep on residential site and Mid-sized commercial projects because the buildings suitable for $200 \mathrm{~kW}$ or smaller solar generations to fit arrays. Hence the microgrid emerge which may need systems integration though it is designed for independent operation. Microgrid can support a flexible and efficient electric grid, by enabling the integration of growing deployments of renewable sources of energy such as solar and wind and distributed energy resources such as combined heat and power, energy storage, and demand response. 
To put it more clearly, does utility have right to refuse small power production or storage after they meet certain standards? In fact, the content of utility's obligation from the initiative PURPA contains three parts: mandatory purchase, non-discrimination rates, and safety management. The last one requires utilities to provide electric service to qualifying facilities in the public interest. Only the "qualifying facilities" is the requirement of grid interconnection concerning risk and safety, nothing about with economy and scale. Therefore, no matter the transmission has operate independently or only function as a sector separate from the others, the utility should not limit capacity of small power production which ask for integration.

Taking into account the technical security and stability of the grid system, recently some utilities slip into the side of caution in their roles of guardians of the grid infrastructure. They think that the more variable sources that are added into the energy mix on the grid, the more that grid has to compensate when the sources are no longer available. This problem can lead to grid instability, which forces utilities to maintain traditional generation sources. Nevertheless, a matter of fact is, with the development of technology, the grid adjustments can be made autonomously, reliably, safely, and quickly.

Since the US has been playing a leading role in the grid integration, however, the shift from utility scale to distributed generation does not go smoothly. Even in 2014, US power markets are still in the early stages of a transformation driven by the adoption of distributed energy. Not only worrying about keeping up with the technology but also worrying change of business model, subsidies reduction from government, and cost increasing etc., the electric utilities generally have defensive attitudes. Of course, this may be mainly because they have never faced so many requirements of interconnection from small power generation facilities pop up. According to analysis from the National Renewable Energy Laboratory (NREL) of U.S., the interconnection with small power generation facilities which are residential or small commercial-scale installation (typically less than $50 \mathrm{~kW}$ ) took an average of 63 business days from the date the PV installer submitted the interconnection application to when permission to operate was granted from the utility [7], although the federal government and states have enacted some law, as well as standard contracts for follow. Also, Interstate Renewable Energy Council (IREC) tried the effort to improve interconnection procedures in states across the country and issued the Interconnection Best Practices [8] which highlight there should be no individual system capacity limit, and all utilities (including municipal utilities and electric cooperatives) should be subject to the state policy.

On the other hand, we review the practices of the "Mandatory Connection and Purchase Policy" in China. In reality, after the electricity "Plant-Grid Separation" reform in early 2002, the largest stateowned electric utilities company in the world- State Grid Corporation of China (SGCC) were divided into two grid companies, five generation groups and four accessorial business companies. SGCC is a utility which transmits and distributes power in China. After the Renewable Energy Law (REL) was enacted in 2006, the State Electricity Regulatory Commission (SERC) [9], pursuant to Article 14 of the Law, issued the Measures on Grid Company Full Purchase of Electricity from Renewable Energy (Full Purchase Measures) in 2007. Besides boosting the capacity of renewable energy, partial reason is the transmission sector is monopolized by SGCC and CSPG respectively, and the distribution and retail sector, more than 80 percent of electricity is also the same sellers in the area. Yet, On December 26, 2009 the final amendments were passed with a significant change to the REL. The amended Article 14 provides that, grid companies still must adhere to the mandatory connection policy, but will now also be required to purchase a set quota of renewable power, as a proportion of their total power purchased [10]. Also, the amended Article 14 requires the relative authorities to set priority dispatch regulations that will give priority to renewable power generators in the electricity dispatch sequence. It is the first time the concept of priority dispatch has been included in the REL, though it was mentioned previously in some concerning regulations. Here, as noted above, the paper emphasize that utility's mandatory purchase obligation is only the subsidy policy matters, and strongly relate to the structure of electricity market which there is no independent transmission operator. Even so, the "Mandatory Connection Principle" should be planned and implement seriously in any case. And especially drawing up legal basis for more variety, smaller, distributed generations that interconnected not for wholesale transactions, but for 
fundamental right of electricity accessing from grid.

\section{Conclusion}

We observed that there are some similar documents issued in Taiwan, and includes the "Technical Code for Interconnection with Renewable Energy System" and the "Standard Agreement for Wholesale of Renewable Energy". Nevertheless, these documents are issued by the Ministry of Economic Affairs, and only for the Taiwan Power Company ("Taipower") established on May 1,1946 and is a vertically integrated power utility. On the whole, following the globe trend, Taipower try best to benefit customers by removing unnecessary obstacles to further development of wind \& solar resources while ensuring that reliability is protected. But, similar to China, centralized PV station still the majority in Taiwan at this present stage, and regrettably, it seems not begin advancing distributed generations and not recognizes the technical differences in the design and operational characteristics of wind generating technology and other alternative technologies. In fact, the content of utility's obligation about safety management requires them to provide electric service to qualifying facilities in the public interest. No matter the transmission has operate independently or only function as a sector separate from the others, the utility should not limit capacity of small power production which ask for integration. This essay emphasizes that utility's mandatory purchase obligation is only the subsidy policy matters, and strongly relate to the structure of electricity market which is no independent transmission operator. Nonetheless, in the near future, the "Mandatory Connection Principle" should be well planned in the Renewable Energy Law and relative regulations.

\section{References}

[1] Source: Short- Term Energy Outlook, U.S. Energy Information Administration; March 2015.

[2] The Regulatory Assistance Project, Electricity Regulation in the US: A Guide; March 2011.

[3] REN21. (2013). Renewables 2013 Global Status Report. [Online]. Available: http://www.ren21.net

[4] International Renewable Energy Agency, REmap 2030-A Renewable Energy Roadmap; June 2014:82-91.

[5] The mandatory connection and purchase policy. Please See Article 14 of the Original Renewable Energy Law.

[6] Jack S. (01-28-2010). China revamps renewable energy law. [Online]. Available: http://m.mayerbrown.com/publications/china-revamps-renewable-energy-law-01-28-2010/

[7] Ardani K, Davidson C, Margolis R, Nobler E. A state-level comparison of processes and timelines for distributed photovoltaic interconnection in the united states. The National Renewable Energy Laboratory, January 2015.

[8] Interstate Renewable Energy Council. (2013). [Online]. Available: http://www.irecusa.org/regulatory-reform/interconnection/

[9] In 2013, SERC and National Energy Administration Merged to form the Current NEA.

[10] Schuman S. Improving China's Existing Renewable Energy Legal Framework: Lessons from the International and Domestic Experience. Natural Resources Defense Council; October 2010:9-10. 